\title{
Vital Signs Original Result
}

National Cancer Institute

\section{Source}

National Cancer Institute. Vital Signs Original Result. NCI Thesaurus. Code C83108.

The outcome of the vital signs assessment. 